\title{
Reform and Exploration on the Management Mode for Maintenance Engineering of the Generator Units
}

\author{
Qun-Yin GU, ${ }^{1, a}$, Hai-Yan $\mathrm{CHEN}^{1, a}$, Ying $\mathrm{SONG}^{2, \mathrm{~b}}$, Xiao-Dan ZHAO ${ }^{3, \mathrm{c}}$, Cui-Yu \\ $W U^{1, a}$ \\ ${ }^{1}$ College of Electric Power Engineering, Shanghai Electric Power University, Shanghai, \\ 200090, China
}

${ }^{2}$ Sichuan Province Electric Power Company Construction Management Center, Chengdu, 610021, China

${ }^{3}$ Sichuan Electric Power Construction Company, Chengdu, 610000, China

aguqy0000@163.com, b451474004@qq.com, c715446610@qq.com

Keywords: Generator units, Maintenance engineering and management, Management model.

\begin{abstract}
On the basis of the maintenance engineering and management system for the existing power plant units, the characteristics and problems of the management mode for maintenance engineering of the existing four power plants were analyzed from the perspective of maintenance engineering and project management. On the other hand, the reform measures of the current power plant maintenance engineering and management system were also discussed in the two aspects of both the external environment and the internal enterprise, which helped improve the competitiveness of enterprises, and promoted the establishment and regulation of the maintenance engineering and management of units, and played a positive role in improving maintenance quality.
\end{abstract}

\section{Introduction}

With the rapid development of China's power industry, the total installed capacity of the generator assembly not only increases quickly, but the unit capacity is also continually rising. $600 \mathrm{MW}$ and $1000 \mathrm{MW}$ thermal power units have been becoming the main units. At present, 1000MW units have made a figure. Since the contradiction between electricity supply and demand is sharping in 2003, our country adjusts the development and Planning programs for the electrical industry, and strengthens electric construction. According to Statistical Communique on the 2013 National Economic and Social Development[1,2] released by National Bureau of Statistics of People's Republic of China, the national thermal power installed capacity was 1.24 billion kilowatts at the end of 2013, which increased by $9.3 \%$ over the end of the previous year (see Table 1), Among which the thermal power installed capacity was 0.86 billion kilowatts with an increase of $5.7 \%$; the hydropower installed capacity was 0.28 billion kilowatts with an increase of $12.3 \%$; the nuclear power installed capacity was 0.014 billion kilowatts with an increase of $16.2 \%$; the on-grid wind power installed capacity was 0.075 billion kilowatts with an increase of $24.5 \%$; the on-grid solar power installed capacity was 0.014 billion kilowatts increasing 3.4 times. The proportion of each type of electricity generation in unit construction during the period from 2009 to 2013 was shown in Fig.1 Under the situation of extraordinary development of electrical industry, the Influences and impacts on maintenance engineering and management for the current thermal power generating units are mainly in the following four areas: 
Table 1 National installed capacity of the power generation equipment 0.1 billion kilowatts

\begin{tabular}{|l|l|l|l|l|l|}
\hline Years & 2009 & 2010 & 2011 & 2012 & 2013 \\
\hline $\begin{array}{l}\text { The total installed } \\
\text { capacity }\end{array}$ & 8.7 & 9.6 & 10.6 & 11.4 & 12.4 \\
\hline New installed capacity & 0.89 & 0.91 & 0.90 & 0.87 & 0.96 \\
\hline Of which: thermal power & 0.61 & 0.58 & 0.59 & 0.51 & 0.45 \\
\hline Hydropower & 0.19 & 0.16 & 0.12 & 0.19 & 0.26 \\
\hline Nuclear power & 0.01 & 0.017 & 0.018 & 0.007 & 0.045 \\
\hline Wind Power & 0.09 & 0.14 & 0.16 & 0.15 & 0.16 \\
\hline Others & - & 0.0019 & 0.017 & 0.0097 & 0.005 \\
\hline
\end{tabular}

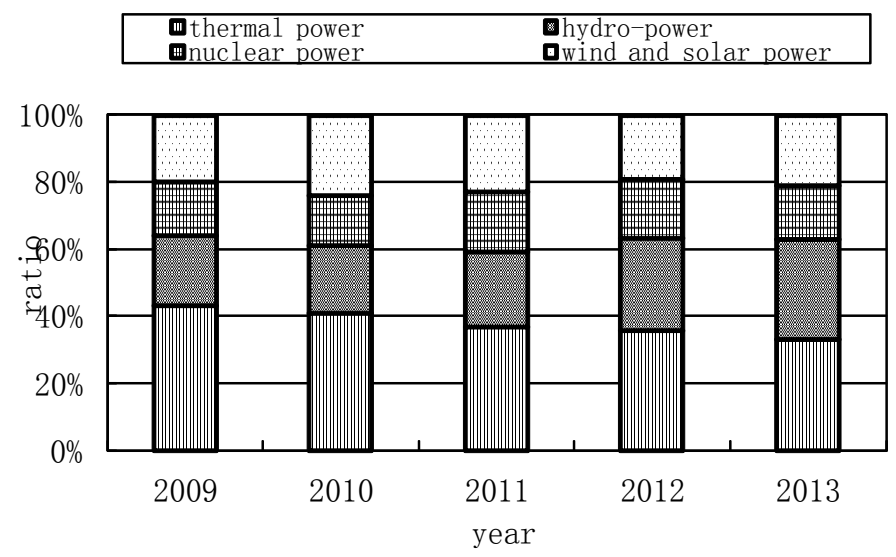

Fig. 1 The proportion of each type of electricity generation in unit construction

Firstly, with the continuous contribution of large-scale units and greatly increased degree of equipment automation, the number of the operators required is accordingly reduced, which results that part of the original operators were transferred to the position of maintenance.

Secondly, despite of the increase of the maintenance period for newly built large-scale units, the number of large-scale units. On the other hand, the newly established enterprises do not commonly allocated a dedicated maintenance team. Therefore, the number of maintenance engineering significantly increases, and the contradiction between maintenance supply and demand becomes increasingly prominent.

Thirdly, the extensive use of maintenance tools that are easy to operate not only improves maintenance quality, but also reduces the labor demand for individual project maintenance. On the one hand, with the increase of the unit maintenance intervals, a large number of maintainers do little maintenance work resulting in idle workforce. On the other hand, due to the large-scale structure of units and its complex systems, the work is much and the shortage of manpower occurs during an overhaul, which needs many temporary workers and job outsourcing repair, resulting in a contradiction "idle for a thousand days but tight for one day's battle." and affecting the improvement of the plant overall labor productivity. Meanwhile, the Internal operation of self-maintenance makes the maintenance team to be in the monopolistic position in the power plant, resulting in the lack of competition, which is bad for the improvement of maintenance quality conducive to maintenance and the level of the maintenance team.

Fourthly, the number of the power generation enterprises which have the ability to complete an overhaul independently is very little, especially the newly built power plants. Therefore, the contradiction between the power plant maintenance supply and demand provides a broad market and living space $[3,4]$.

\section{Analysis on present situation of management mode for maintenance engineering}

Maintenance engineering and management for the domestic power generation enterprises the existing power plant units can be divided into the four main modes: 
(1) The thermal power plants not having the maintenance sectors, distribute maintenance work to the branch companies or subsidiaries;

The characteristics of this management model are that maintenance work is undertaken by the maintenance subordinate companies or subsidiaries of the thermal power plants not having the maintenance sectors, and the projects by subcontract do not have competitive bidding features. This maintenance management model promotes the development of the power enterprises reforming and the electric maintenance systems to some extent, which greatly improves than the former self-contained and closed model in terms of technologies and the maintenance quality.

(2) Maintenance work is undertaken by the independent accounting maintenance sectors of the power generation subordinate companies;

This model is that the maintenance sectors are rooted in the power generation enterprises, and the corporate plants are strong backing in the aspect of financial resources, human and material resources. It is relatively independent in the operation mode, which can operate in accordance with the basic law of market-oriented economy in terms of the maintenance operation [5]. It is characterized by independent accounting and relatively independent business. The shortcoming is that the contractual relationship is not built upon real Marketing bidding for the internal power generation enterprises, therefore the maintenance quality and costs are relatively difficult to control.

(3) Maintenance engineering is the planning task of the sector for the power generation enterprise having the maintenance sector;

The enterprises belong to this mode account for a large proportion, especially some old enterprises. These companies basically follows the traditional maintenance management model, which are based mainly on maintenance work of their companies', but they do not completely abandon the competitive advantages in the electrical maintenance markets and regard the external maintenance business as a method to make profits. This is characterized by a planned economy model, and the relationship between the maintenance sectors and the enterprises are a superior-subordinate relationship, which results in the lack of market competition in maintenance engineering and the lack of an effective monitoring system, leading to maintenance quality and the cost of projects difficult to control. In addition, this mode is not conducive to competition in the electrical maintenance market, and is not conducive to the improvement of its technical levels either.

(4) Bids are invited for maintenance engineering in the power maintenance markets for the power generation enterprise not having the maintenance sector.

The characteristics of this kind of power generation enterprises is that maintenance engineering are fully market-oriented operation in an overhaul. The electrical maintenance markets implement projects bidding publicly, which carries out modern project management. This maintenance mode is mainly used in the newly-built power generation enterprises.

\section{Reform feasibility of the management mode for maintenance engineering of the power generation enterprises}

In view of the reform of the electricity business, our country promulgates Program on Reforming the Power Industry. The overall objective of the reform program is to break the monopoly, introduce competition, increase efficiency, reduce costs, improve electricity price mechanism, optimize resources allocation, boost the electric power development, promote nationwide interconnection, and built an electricity market with separation of government and enterprises, fair competition, opening and order, and healthy development under the supervision of government. According to this overall objective, in order to improve power generation quality, reduce costs and enhance competitiveness in the "separation of plant and network, bidding for use of network". It is imperative to reform the maintenance system for the power generation enterprises. The unit maintenance project must be carried out through tendering procedure, and is undertaken by the completely independent and professional power maintenance company. The advantages of the maintenance system reforming are as follows $[6,7]$. 
(1) The rapid development of China's power industry, the construction of a large number of new power plants and the multiplied installed capacity provide a market for the maintenance company to step into the society.

(2) The structural reforms provide a "new approaches for new plants" program and prescribe that the newly added and built power generation companies no longer staff maintenance personnel. Therefore the old power plants having maintenance personnel will be responsible for the maintenance tasks of the old plants and the new plant units.

(3) Many power maintenance teams accumulate abundant maintenance experience for high-parameter and high-capacity units over the years, which have a clear understanding for fault laws and fault periods of equipment and have plenty of first-hand information, leading to a great increase of the degree of specialization.

(4) The progress and development of power monitoring techniques and systems analysis technologies make monitoring and analysis of the equipment conditions effective. They can judge the equipment conditions objectively and scientifically.

(5) The improvement of the staff's technical levels makes implementing the advanced maintenance management system possible in our country. After years of training, a skilled personnel group forming in China's electric power system, are capable of finishing equipment monitoring, analysis and judgment of the whole process work, which provides personnel preparations for reforming China's electric power maintenance and management.

(6) The modern management of thermal power plants urgently needs that contract award of maintenance work should follow the market rules.

\section{Reform and exploration on the management mode for maintenance engineering of the units}

According to the overall goals of the electricity system reforming, the newly added and built power generation companies no longer staff maintenance personnel in the future. Although the old power generation enterprises staff maintenance personnel, maintenance engineering of the power generation enterprises, which is born out of planned economy and new and in the transition from the old structure to the new, is gradually changing concepts and stepping into the market for the moment ${ }^{[8,9]}$. Therefore, analyzing and researching the current status of the contract awarding system for maintenance engineering of the power generation enterprises, and discussing the current reform measures of the contract awarding system for maintenance engineering, will play a positive role for improving the competitiveness of enterprises and establishing and regulating the competition mechanism of the maintenance market. Specific reform measures are as follows:

\section{Aspects of the external environment}

(1) Government should formulate the relevant policies and regulations to provide a legal basis for system reforming.

Maintenance engineering of the power generation enterprises can refer to the relevant provisions of the State [10], and regulate the bidding system for maintenance engineering through the establishment of industry and local regulation system. For example, the provisions of the construction industry can be referred: the projects with a building area above 500 square meters must be carried out with public bidding regardless of design and construction, otherwise design or construction is forbidden. The electric power industry can also regulate that the maintenance projects of the power generation enterprises must be carried out with public bidding, and regulate the bottom line of public bidding, such as the bidding required for project investments above 200,000 RMB to regulate the electrical maintenance market.

(2) Public bidding can use the building trade center of the existing construction industry to release information.

After many years of construction industry reforming, an improved building trade center has been established in all provinces and cities, and all the construction project bidding must be held in the designated trade center buildings. The release of information and its operation of bidding already 
have mature management experience. The bidding of the electrical maintenance projects can take place in the existing building trade center or platform.

(3) Establish an expert tank for evaluating electrical maintenance engineering to ensure that the evaluation results are fair and impartial.

In order to standardize bid evaluation for the maintenance projects, break industries and regions monopoly, and prevent the occurrence of improper trading, resource sharing of the expert database of electrical maintenance engineering can be achieved through the establishment of an expert tank for evaluating power maintenance, and ensure that the evaluation results are fair and impartial.

(4) Industry associations need to protocol the necessary norms and rules to guide the enterprises to orderly and fair competition.

In increasingly fierce competition in the power plant maintenance market, industry associations should play an active coordinating role. Industry associations should make some necessary rules to guide enterprises to compete orderly and fair in the aspects of without control of government and enterprises unable to manage by themselves.

(5) Build an assessment mechanism for quality and security costs for the leaders of the power generation enterprises.

The superior sectors will take maintenance quality costs and security costs as one of indexes for assessing operators operating levels through the establishment of operators' evaluating mechanism for power generation enterprises. This will help to change the practices that do not consider the costs and quality. The purchase of the electrical maintenance equipment is undertaken by the maintenance enterprises, which can eliminate a lot of spare parts wasting, prompt the maintenance enterprises strictly control the quality and enhance the sense of responsibility.

(6) Improve the quality of the maintenance projects, and establish relevant project supervision and regulations.

Although there have been the supervision companies, the most of enterprises does not hire a professional supervision company to supervise in the maintenance project since there are no corresponding regulations. Project supervision lack of standardization will be difficult to achieve true control of project quality, schedule and costs. The maintenance system of the power generation enterprises and supervision system of the maintenance project must be improved to ensure the quality of the maintenance project.

\section{Aspects of enterprises interior}

(1) Establishing the sustainable development strategy for the maintenance companies.

The trend of reforming the power maintenance system is to be independent enterprises of complete "four selves". As a present maintenance company facing a severe test of what path to follow, the sustainable strategy is the soul of enterprises. The power generation enterprises in the reform correctly handle the relationship with the maintenance companies, target marketization, transit in a planned way, grasp the pulse of power reforms and draw up the development strategy of enterprises in accordance with power industry.

(2) Creating conditions to change the management mode for maintenance engineering

The maintenance mode in the last planned economy period is essentially closed and single, and is mainly administrative intervention no matter what problems. In the future, the power maintenance mode cannot use single means of management to adapt the market economy law, face the market, optimize the structure and improve the overall strength. The power generation enterprises should create conditions, deal with the various relationships, complete power plant maintenance reforming and scientifically manage the maintenance project.

(3) Further improve the economic management mechanism for the maintenance companies interior

At present, there are different operation modes in different electrical maintenance systems, such as independent accounting, contracted management, joint-stock form and so on. Changing the original ownership structure of state-owned enterprises, achieving the ownership structure diversifying, clarifying and socializing property rights, and clearing identity of staff lay a good foundation for the sustainable development of enterprises; on the other hand, they also can create basic conditions for 
absorbing social capital in the future, introduce strategic partners, and enhance capital strength and profitability of net assets.

\section{Conclusions}

The separation of a power maintenance team from the thermal power plants and the establishment of a specialized maintenance company are the inevitable requirements for the current electricity market reforming and the "separation of plant and network, bidding for use of network". Only fully entering the market, the cost of electricity can be reduced; only digging out the potential of bidding, the greater social and economic benefits can be obtained. Creating a unified, open, competitive and orderly power maintenance market through taking corresponding measures and proper transition can make the thermal power plants and the power maintenance companies to survive and develop in competition and to obtain a win-win situation for adapting the needs of national economic development.

\section{References}

[1] National Bureau of Statistics of the People's Republic of China, Statistical Communique of National Economic and Social Development in 2013, 2013.

[2] China Business Market Research Reports and Industry Analysis (http://www.askci.com/), Forecasting analysis on the installed capacity of power generation equipment during the period from 2013 to 2014, Dec. 13rd, 2013.

[3] A significant relief of the power shortage situation in 2005, Xinhuanet of Beijing, Dec. 2003.

[4] Zhu Zhanfang, Wang Wei. primary ideas of direction of repair system reform in thermal power plants in our province. Guangdong Electric Power, 1999, Vol. 12, No.4, pp 5-9.

[5] Dong Peijun. The reform trends of the maintenance system of thermal power enterprises. China Power Enterprise Management, 2002, Vol.8, pp 40-41.

[6] Zeng Ming. Several problems of the thermal power plants entering the market. Electric Power Operation and Management, 2000.

[7] $\mathrm{Wu}$ Xirong. New world development of the electric power maintenance. Chinese Power Enterprise Management, 2001, Vol.11, pp 33-34.

[8] Li Qiangde. reforms of the management system of the power plant maintenance. Sichuan Electric Power Technology, 2001, Vol. 4, pp 59-60.

[9] Fang Jian. Full of spring vitality for the old pants in the maintenance system reform. Shanghai Electric Power, 2000, Vol. 1, pp 22-23.

[10] Feng Tian, Yu Wenlong. Discussion on the Chinese power plant maintenance system. The Thermal Power Generation, 2002, Vol. 2, pp 12-14. 